\title{
Psychosocial Support Interventions for Children with a History of Maltreatment: The Situation in the East African Community. An Integrative Systematic Review
}

\author{
Eunice. M. Ndyareeba (MED) ${ }^{1 *}$, Nabukeera Madinah $(\mathrm{PhD})^{2}$, Godfrey Ejuu (Associate \\ Professor) $)^{3}$ \\ ${ }^{1}$ Department of Educational Psychology, Kabale University, Kabale, Uganda \\ ${ }^{2}$ Department of History and Political Science, Kyambogo University \\ ${ }^{3}$ Early Childhood Development Department, Kyambogo University, Uganda, East Africa
}

*Corresponding Author: Eunice. M. Ndyareeba (MED), Department of Educational Psychology, Kabale University, Kabale, Uganda

\begin{abstract}
Psychosocial support is an integral aspect for consideration while mitigating the devastating effects of child maltreatment. There is scarcity of research regarding available psychosocial support intervention for maltreated children in developing countries. This systematic review aimed at establishing child protection and care policy, available psychosocial support interventions for children with a history of maltreatment in the East African community. On line data bases and gray literature from WHO website published between 2015 and April 2020 were searched. This systematic review stipulates the existing psychosocial interventions in East Africa, their effectiveness, acceptability and appropriateness which is useful information for adolescents, families, education stakeholder and policy makers. It is recommended that psychosocial support interventions to mitigate child maltreatment in East Africa ensure to focus on children and adolescents as primary encounters of violence, be age appropriate and gender specific since there are gender-based variations in the effects of maltreatment.
\end{abstract}

Key terms: Child Maltreatment, Abuse, Neglect, Violence, Psychosocial Support Interventions, Adolescents

\section{BACKGROUND}

Child development is a critical process which requires a supportive environment from a person's immediate family members, peers and the community as key agents of care and protection (1). Global reports, however, have persistently presented child maltreatment as an evident phenomenon estimated to be affecting one billion children annually and $77.5 \%$ of the perpetrators are parents (2). There is an association between child maltreatment and devastating lifelong consequences to individuals who experience it $(3,4)$. Child maltreatment refers to sexual abuse, physical and emotional abuse and neglect and witnessing violence during the first 18 years of life (5). Though child-maltreatment occurrences are well documented in developed countries $(3,6-8)$, there is still scarcity of research in developing and low income countries (9). Anecdotal reports also have it that other millions of child maltreatment cases are unreported because the African tradition of the extended family child care and protection has been interfered by the economic changes and the pressure it exerts on families.

Adolescents are at a greater risk of suffering maltreatment because this transitional stage from childhood to adulthood causes them to question authority, break rules and take risks yet at the same time it is a prime stage of development that requires support from adults to help adolescents sail through successfully (10). Such a paradox presents a gap that requires the understanding of how best children and adolescents with a history of adverse experiences can be supported. Child maltreatment risk is even greater for children and adolescents from vulnerable among refugees (11), low and middle income settings (12), and alcohol and drug addicted parents (5). It is thus plausible to understand the effectiveness of psychosocial support by synthesizing evidence- based studies done in East Africa in a bid to mitigate the devastating consequences of child maltreatment which include interference with 
physical, mental and emotional functioning consequently resulting in a big socio-economic burden on families, communities and the nation.

Interventions geared towards mitigating the effects of child maltreatment that include not only the affected individual but also other members meant to provide care and protection to children and adolescents are vital (13). In a bid to achieve SDG education Target 4.a "provision of safe, non-violent, inclusive and effective learning environments for all", world health organization in partnership with other evidence-based research implementers supports interventions to lessen child maltreatment and its effects on the victim's wellbeing.

Psychosocial support is one of the double edged (preventive and curative) interventions adopted by different evidence-based implementers in developed countries by providing cognitive behavioral therapy (CBT), home visitations and psycho education on positive parenting to children and parents or other primary caregivers (14). In East Africa psycho education in training workshops: interaction competence with children for teachers (15) and integration of psycho education in vocational training programs for refugees have been embraced (16). Intervention implementers allude to existing evidence that psychosocial support strengthens parent-child relationships, reduces adolescents' maltreatment deficits at the time of follow-up (17). This implies that there is hope for a maltreated adolescent especially if focused social support is provided (18). While there is evidence on psychosocial support interventions for maltreated children and adolescents in developed countries, information on the delivery, coverage and effectiveness is lacking especially in low-income countries. It thus presents a gap for understanding the effectiveness of the psychosocial support interventions for particular vulnerable categories in different settings. For example, maltreated children and adolescents from low income families in East Africa given the uniqueness of environmental characteristics and different forms of abuse experienced. This can only be achieved if a systematic review is done to categorize the existing psychosocial support interventions, accessibility, acceptability and appropriateness. This systematic review documents the available psychosocial support interventions for maltreated children in terms of procedures, acceptability and accessibility.

\subsection{The General Picture of Existing Psychosocial Support Interventions for Children with a History of Maltreatment}

One of the multilevel psychosocial support interventions (parenting skills training, psychiatric treatment and psycho education services) done in a health care setting in Iran, at three- and six-months follow-up found that child-parent interaction greatly improved, and child maltreatment reduced (13). We allude to the above findings to assretain that pscyosocial support is a necessity for adolescents in this century more than ever before due to the developmental challenges given the nature of the society characterized by high costs of living, conflict at family and community levels, swift changes in technology and digitalized communication all which increases exposure to maltreatment experiences.

Moreover, in the theoretical lens, Child maltreatment is well described by the ecological models of child development as a multifaceted contextual problem that requires a systematic approach to explain all influential factors (1). This implies that to address maltreatment issues, consideration of support factors inclined to an individual's interaction is paramount. Therefore, interventions that involve maltreated children and their parents are worth considering. Below is an explanation of how different spheres of an individual's interaction contribute to child care and protection or maltreatment experiences. At the individual level, a child's behavioral characteristics may cause him or her to be maltreated for example if a child is ant-social. developmental retardation may cause neglect. At family level, parenting skills, mental health problems of the parent and parental addictions exposes children to maltreatment and the community perspectives of child care and protection also have a contribution $(19,20)$. The ecological model therefore underpins the rationale for inclusion of evidence -based psychosocial interventions which focus on both the involvement of maltreated children, their parents and other primary caregivers as path ways through which implementation of curative and preventive measures to mitigate adverse child maltreatment effects.

It is therefore vital to include both parents and children in interventions as it serves as a double aged treatment that is both curative and preventive. However, since at the age of 12 children transit to independence and parents may no longer have great influence, it is important to consider interventions that address adolescents psychosocial support needs directly. Though some children with a history of maltreatment may develop resilience to sail through the adverse conditions successfully, it is not fully 
understood how these particular children cope. Therefore, focused psychosocial support for vulnerable children and adolescents is paramount considering the adverse developmental outcomes linked to maltreatment experiences (21).

\subsection{Rationale for this Review}

In the developed setting, considerable research on the effectiveness of psychosocial support mitigating adverse effects of child maltreatment has been done. For example, in the UK, an evaluation study found out that most of the psychosocial support interventions for maltreated children were never evaluated yet a few consultations from the participants' perspectives, found out that considerable number of interventions did not address the pertinent aspects (14). The situation may be alarming for developing countries where maltreatment cases are higher compared to developed countries. It thus presents a gap which require the documentation of forms of psychosocial support interventions that have been implemented in developing countries and any possible child care and protection policy, particularly in East Africa. The main question to be answered by this review paper is; have the existing psychosocial support interventions for maltreated children and adolescents addressed the specific maltreatment forms appropriately in different settings? The aim of this review will be to; categorize psychosocial support interventions according to their effectiveness on mitigating adverse effects of different forms of maltreatment and to document the challenges involved in implementation of psychosocial support interventions in East Africa. The documentation of psychosocial support interventions for children with a history of maltreatment in East Africa is of paramount importance to evidence- based implementers by enhancing focused psychosocial support to appropriate maltreatment forms. The results of this review are useful for stakeholders who implement psychosocial support for children below 18 years in the aftermaths of maltreatment.

This integrative review documents the psychosocial support interventions for children with a history of maltreatment to mitigate adverse effects of different forms of maltreatment experienced by children under 18 years in East Africa. This review informs the future psychosocial support (PSS) implementers and researchers among maltreated children and adolescents in low income settings.

\section{MeTHODS/DESIGN}

This systematic review took the integrative review approach and the report was written according to the guidelines recommended by Preferred Reporting Items for Systematic Reviews and Meta-Analyses PRISMA (22). On line data bases searched included google scholar, PsycINFO, and gray literature from WHO website published between 2015 and April 2020. The search terms included "Child Maltreatment" AND "Psychosocial support AND "interventions" AND Adolescents"; Child Maltreatment" OR "Child abuse" AND OR "Neglect". The research team identified potentially relevant research papers and reports that summarize series of studies. Both qualitative and quantitative evidencebased studies that included psychosocial support for children and adolescents with a history of child maltreatment in the first 18 years of life, done in East Africa were included. Primary empirical research published in English between 2015 and April 2020 where participants included children, adolescents and parents and or other primary caregivers or other stakeholders like teachers, school heads and school counsellors were legible for this review. The research team identified 7 studies which were legible for inclusion. Of the seven, three studies were program evaluations and four were published papers. Included articles are shown in the table below;

\begin{tabular}{|l|l|l|l|l|}
\hline AUTHOR & YEAR & TITLE & SOURCE & $\begin{array}{l}\text { NATURE OF } \\
\text { THE STUDY }\end{array}$ \\
\hline $\begin{array}{l}\text { Siua, C, G. E. } \\
\text { Wightb, D. Seeleyc, } \\
\text { D, Namutebia, J. C. } \\
\text { Sekiwungaa, R. } \\
\text { Zalwangoc, F and } \\
\text { Kasule, S. }\end{array}$ & $\begin{array}{l}\text { Men's Involvement in a Parenting } \\
\text { Programme to Reduce Child } \\
\text { Maltreatment and Gender-Based } \\
\text { Violence: Formative Evaluation in } \\
\text { Uganda }\end{array}$ & Pganda & Published paper \\
\hline Knight et al. & 2018 & $\begin{array}{l}\text { Implementation of the Good School } \\
\text { Toolkit } \\
\text { in Uganda: a quantitative process } \\
\text { evaluation of a successful violence } \\
\text { prevention program }\end{array}$ & Uganda & Published paper \\
\hline
\end{tabular}


Psychosocial Support Interventions for Children with a History of Maltreatment: The Situation in the East African Community. An Integrative Systematic Review

\begin{tabular}{|l|l|l|l|l|}
\hline $\begin{array}{l}\text { Psychosocial, } \\
\text { National } \\
\text { Guidelines, Support } \\
\text { Children, } \\
\text { Vulnerable }\end{array}$ & 2015 & $\begin{array}{l}\text { Department of Children Services } \\
\text { National Psychosocial Support } \\
\text { Guidelines for Orphans and } \\
\text { Vulnerable Children }\end{array}$ & Program report \\
\hline Child Care Reforms & 2015 & $\begin{array}{l}\text { An Analysis of Child-Care Reform in } \\
\text { Three African Countries Summary of } \\
\text { Ghana Rwanda. March. }\end{array}$ & Rwanda & Program report \\
\hline Mutavi et al. & 2018 & $\begin{array}{l}\text { Incidence of depressive symptoms } \\
\text { among sexually abused children in } \\
\text { Kenya. }\end{array}$ & Kenya & Published paper \\
\hline WHO & 2019 & $\begin{array}{l}\text { Who Guidelines For The Health Sector } \\
\text { Response To Child Maltreatment }\end{array}$ & $\begin{array}{l}\text { Kenya, } \\
\text { Tanzania }\end{array}$ & Report \\
\hline Kaltenbach et al. & 2017 & $\begin{array}{l}\text { Improving Interaction Competencies } \\
\text { With Children-A Pilot Feasibility } \\
\text { Study to Reduce School Corporal } \\
\text { Punishment }\end{array}$ & Tanzania & Published \\
\hline
\end{tabular}

\section{RESUlts}

\subsection{The Existing Child Care Policy in East African Community}

The East African community recognizes child care and protection and, in a bid, to strengthen the systems different countries have laid strategies to ensure effective implementation of children rights to ensure child wellbeing. For example, the government of Kenya stipulates clearly the rights of children in article 53 of their constitution and emphasizes child protection against abuse and neglect which constitute all forms of maltreatment (23). Such children protection strategies are based on assumptions that the community members will take on the policies as "do or die' procedures. However, in reality, policies alone may not eliminate child abuse and neglect. This is possibly why maltreatment cases are still on increase in communities where the constitution clearly embraces child care and protection against abuse. It is thus important to expand horizons in understanding possible practical interventions that focus on children wellbeing despite devastating experiences.

In Uganda, the child care and protection policy is not so different from the rest of the East African Community countries. Children rights are recognized and there is legal framework for protection and promotion of children's wellbeing enhanced through the enactment of the Children (Amendment) Act 2016. In addition, the national budget acknowledges child focused sectors under "save the children" to implement measures and structures to prevent and respond to violence affecting children. Uganda's vision concerning children is to have a world in which every child attains the right to survival, protection, development and participation (24). It is clear that the government of Uganda has a powerful policy to protect children and strides have been made to protect children against violence but one wonders why there is still prevalence of all forms of maltreatment in communities. More so the policy may need to look into the fate of children and adolescents who experience violence considering its devastating effects on general life success of the victims.

In 2011 Rwanda, Integrated Child Rights Policy approved national care policy for children in alternative care families. In the same summit, approval of Law 22/2011 establishing the National Commission for Children, law 54/2011 on Rights and Protection of Children and adoption of the Strategic Plan for the Integrated Child Rights Policy (25). This was mainly done to support and strengthen care for children living under alternative care families following devastating psychological challenges in the aftermath's of 1994 genocide.

\subsection{Psychosocial Support Interventions: The East African Community Situation}

In Uganda, psychosocial support interventions both at community and school level have been done in the central region $(26,27)$. A community-based study done by Siu and colleagues termed as 'parenting for respectability program' one of the psychosocial support interventions involving parents of children aged 0-17 years was done at community level. Though the study involved men and women in training positive parenting, the main idea was inclusion of men in parenting to minimize child maltreatment. After 21 successful training sessions (10 single group sessions for men and 21mixed sex sessions), the follow up results revealed that parent-child relationships had improved and parents reported dramatic 
positive changes in their relationships which is a driver to children wellbeing. What this study leaves un attended to is whether children experienced positive change directly because only parents were actively involved in the intervention.

In addition to the above, a school-based intervention, the "Good school talk kit" was done in Uganda as a randomized control trial with an aim to end child maltreatment in schools. The good school talk kit was an 18 months project including 1921 students and 286 staff. The teacher talk kit exposure had larger decreases in violence. However, adjusting for individual talk kit exposure, after the study, students were still at a high risk of experiencing violence. Though, good school talk kit reduced physical violence by $42 \%, 31 \%$ were still at risk of experiencing violence even after the intervention (27). This implies that there are forms of abuse that require specialized support other than just creating awareness about children rights and how to report and avoid abuse. This is in agreement with fundamental guidelines for holistic psychosocial support for rounded wellbeing of maltreated children in Kenya which stipulates effective PSS that is age and gender sensitive (28).

The government of Kenya also recognizes, that much as children are a pertinent facet that makes up society, for some good decades they have been faced with challenges of maltreatment resulting from orphan hood, poverty HIV, wars and risks related to negative use of technology which require not just visible support but also invisible support mainly psychosocial support. To this effect standard guidelines for effective psychosocial support at child level were stipulated in the 2015 report emphasizing age specific and gender appropriate approaches (29). The existing psychosocial support intervention done in Kenya has mainly focused on HIV orphaned children and children and adolescents living with HIV (29).

Moreover, most of the interventions for maltreated children in Kenya have mainly focused on addressing tangible necessities like food, clothing and shelter ignoring the non-tangible needs like psychosocial support (23). Unfortunately one of the studies done in Kenya found out that children suffered sexual abuse which caused then depression (30). The same report presented that there were no international guidelines for offering psychosocial support. Recommendations to include psychosocial support in the health care facilities to provide adolescent friendly mental health care services for maltreated children were presented. No doubt, such cases may not be effectively addressed by provision of tangible support, therefore there is need for focused psychosocial support.

Following genocide, Rwanda is one of the East African Community countries with the concrete actions to reform and strengthen child care systems to ensure child wellbeing. The support in Rwanda is mainly for orphans and unaccompanied children and those whose rights a violated in one way or the other. Residential care facilities based on 'One Child-One Family' Campaign promotes family-based care for maltreated children since the aftermath of genocide (25).

In Tanzania, schools based psycho social intervention to reduce corporal punishment against children by teachers was done focusing on strengthening interaction competences with children for teachers (ICC_T). Findings of this study indicated that feasibility was good and accessibility was effective. On follow up, the ICC-T core values were highly adopted and teacher/ child interaction behavior had improved. The same study recommended future studies geared towards sustainability (31).

\section{DISCUSSION}

Findings of psychosocial support intervention studies done in the East African community were successful in as far as acceptability and effectiveness is concerned at the time of follow up. This was for studies done in Uganda, Kenya, Tanzania, Rwanda and it is in agreement with other studies that have been done in developed countries $(13,15,32)$. This implies that implementation plans were feasible and selected participants embraced the interventions. What is not known is the sustainability aspect and therefore a gap that can be bridged by longitudinal studies to follow up the impact of psychosocial support interventions for children with a history of children in the same settings.

In addition to the above, findings from the reviewed studies show that psychosocial support for children with a history of maltreatment experiences is offered differently for different countries but implementers mainly focus on the perpetrators of maltreatment as the main agents of change and as paths ways to positive interaction between child and caregiver. In central Uganda for example positive parenting through men involvement in the parenting process was done (26) and another study focused on good 
school talk kit to sanitize children and teachers on understanding child protection benefits (27). This implies that Uganda as a country has not had sufficient intervention for children and adolescent with a history of maltreatment. For any intervention to be effective, the beneficiaries must have their specific needs addressed. This is suggested in one of the reports that stipulates international guidelines for social support (33). Though some studies report improved parent -child and teacher child interaction respectively $(13,15)$, it is not very clear whether the devastating consequences of maltreatment experiences among children and adolescents are addressed.

It is also worth noting that some maltreatment forms require specialized support offered by trained personnel for example the sexually abused children with post-traumatic stress disorders. However, it is only in some of the developed countries that specialized support was given in longitudinal study where medical staff followed up children from birth providing cognitive behavioral therapy (CBT), home visitations and psychoeducation on positive parenting to parents and or other primary caregivers (14). This focused psychosocial support yielded positive parenting and improved physical and psychological wellbeing of children. This implies that it is prudent for researchers to investigate whether maltreated children are satisfied by the received social support or not because not all forms of maltreatment can be successfully addressed in a similar manner.

Rwanda merged as one of the countries of the east African community that has concrete actions to ensure child care and protection well spread in the nation. No wonder, the intervention done bears uniqueness in that its focused on maltreated children as the direct beneficiaries on the services. The only part of family involvement is by resettling the maltreated children in conducive homes that have positive parenting practices which is different from other countries where parents are trained positive parenting skills as a path way for children wellbeing. In addition, the inclusion criteria were focused on orphans and unaccompanied children implying that maltreated children that are neither orphans or unaccompanied are left out. Yet global reports on maltreatment suggest that the main perpetrators of maltreatment were parents (77.5\%); followed by relative but not parent (6.4 percent); multiple relationships (4.2 percent) and "other" who include maids, step siblings are estimated at 4.0 percent (2). Anecdotal reports also have it that other millions of child maltreatment cases are unreported especially in countries where the reporting systems are not streamlined.

\title{
5. CONCLUSiON
}

In the East African community, there is evidence of child maltreatment occurrences including sexual abuse, physical abuse, emotional abuse and neglect despite the existing child care and protection policies. Psychosocial support interventions for maltreated children in East Africa is mainly focused on psycho education on positive parenting and strengthening teacher -child interaction.

Based on this review findings it is important to note that psychosocial support interventions for maltreated children are not gender sensitive and age appropriate for effective outcomes. In addition, psychosocial support should be focused on the nature of maltreatment experienced for example a child who has suffered sexual abuse may require support different from the one who has suffered physical abuse since the two different CM form lead to different psychosocial deficits such as depression and aggression respectively. More over the interventions that have been done do not cater for gender difference and are not age sensitive. This leaves a gap that calls for attention from researchers and intervention implementers to address.

In addition to the above, it important to do follow up of the intervention to care about sustainability of the core values because a three- or six-months' time lag after the intervention may not be enough to predict the impact of the intervention on behavior change.

\section{LIMITATIONS}

Findings of this study are limited to the East African Community and not all data bases were searched.

\author{
AbBreviations \\ PSS Psychosocial support \\ CM Child maltreatment \\ PRISMA Preferred Reporting Items for Systematic Reviews and Meta-Analyses \\ WHO World Health Organization
}


Psychosocial Support Interventions for Children with a History of Maltreatment: The Situation in the East African Community. An Integrative Systematic Review

ICC_T Interaction Competences with Children for Teachers

\section{COMPETING INTERESTS}

The authors declare that they have no competing interests.

\section{FUNDING}

This research did not receive any specific grant from funding agencies in the public, commercial, or not-for-profit sectors.

\section{Authors' CONTRIbutions}

Eunice Ndyareeba participated in the conception and design of the study, searching for literature, interpreted the findings of the existing studies and drafted the manuscript. Nabukeera, M. and Ejuu, G. revised the manuscript.

\section{ACKNOWLEDGEMENTS}

We are grateful to Kyambogo University and Makerere University and Kabale University Online Library teams for their assistance in helping us with the links to access the current literature on different data bases.

\section{REFERENCES}

[1] Hayes N, O'Toole L, Halpenny AM. The Bioecological Model Of Human Development. Introd Bronfenbrenner. 2018; 13-27.

[2] U.S Department of Health \& Human Services, Administration on Children and Families, Administration on Children Youth and Families, Children's Bureau. Child Maltreatment 2018. 2020;

[3] Hillis S, Mercy J, Amobi A, Kress H. Global Prevalence of Past-year Violence Against Children: A Systematic Review and Minimum Estimates. 2019;137(3).

[4] Meng X, Fleury MJ, Xiang YT, Li M, D’Arcy C. Resilience and protective factors among people with a history of child maltreatment: a systematic review. Soc Psychiatry Psychiatr Epidemiol [Internet]. 2018;53(5):453-75. Available from: http://dx.doi.org/10.1007/s00127-018-1485-2

[5] Tran NK, Van Berkel SR, Van IJzendoorn MH, Alink LRA. The association between child maltreatment and emotional, cognitive, and physical health functioning in Vietnam. BMC Public Health. 2017;17(1):1-13.

[6] Abuse C. Understanding Child Abuse and Neglect. National Academies Press; 1993.

[7] Thomlison B. Characteristics of Evidence - Based Child Maltreatment. 2017;(September 2003).

[8] Lamis DA, Wilson CK, King NM. Child Abuse, Social Support, and Social Functioning in African American Child Abuse, Social Support, and Social Functioning in African American Children. 2014;(October).

[9] Forum TACP. African Reort on Violence against Children. 2014.

[10] UNICEF Office of Research-Innocent Florence. The Adolescent Brain: A second window of opportunity. 2017;1-72. Available from: www.unicef-irc.org

[11] Ainamani HE, Elbert T, Olema DK, Hecker T. Ptsd symptom severity relates to cognitive and psycho-social dysfunctioning - a study with congolese refugees in Uganda. Eur J Psychotraumatol [Internet]. 2017;8(1). Available from: $\mathrm{http}: / / \mathrm{dx}$.doi.org/10.1080/20008198.2017.1283086

[12] Purgato M, Gross AL, Betancourt T, Bolton P, Bonetto C, Gastaldon C, et al. Focused psychosocial interventions for children in low-resource humanitarian settings: a systematic review and individual participant data meta-analysis. Lancet Glob Heal [Internet]. 2018;6(4):e390-400. Available from: http://dx.doi.org/10.1016/S2214-109X(18)30046-9

[13] Derakhshanpour F, Hajebi A, Panaghi L, Ahmadabadi Z. Effectiveness of psychosocial interventions in abused children and their families. Med J Islam Repub Iran. 2017; 31(1):283-8.

[14] Macdonald G, Livingstone N, Hanratty J, Mccartan C, Cotmore R, Cary M, et al. Health technology assessment. 2016; 20(69).

[15] Kaltenbach, Hermenau, Nkuba, Goessmann \&, Hecker. Improving Interaction Competencies With Children-A Pilot Feasibility Study to Reduce School Corporal Punishment. J Aggress Maltreatment Trauma. 2018;27(1):35-53.

[16] Horn R, Boniface D, Manikese J, Dijkman L, Alobaidi AKS, Ford DJ. Volume 7 , Number 2 Contents. 2009; $7(2)$. 
[17] Kelly ME, Duff H, Kelly, SaraKelly ME, Duff H, Kelly S, McHugh Power JE, et al. The impact ofsocial activities, social networks, social support and social relationships on the cognitive functioning of healthy older adults: A systematic review. Syst Rev. 2017;6(1).

[18] Irigaray TQ, Thais J, Pacheco B. Child Maltreatment and Later Cognitive Functioning: A Systematic Review Child Maltreatment and Later Cognitive Functioning: A Systematic Review. 2013 ;( January).

[19] Darling N. Ecological Systems Theory: The Person in the Center of the Circles. Res Hum Dev. 2007;4(34):203-17.

[20] Rosa EM, Tudge J. Urie Bronfenbrenner's Theory of Human Development: Its Evolution From Ecology to Bioecology. J Fam Theory Rev. 2013;5(4):243-58.

[21] Cohen, Mannarino, Murray I\& R. Psychosocial interventions for maltreated and violence-exposed children. J Soc Issues. 2006;62(4):737-66.

[22] Liberati A, Shamseer L, Moher D, Clarke M, Ghersi D, Petticrew M, et al. PRISMA-P (Preferred Reporting Items for Systematic review and Meta-Analysis Protocols ) 2015 checklist : recommended items to address in a systematic review protocol *. Bmj. 2015;349(jan02 1):g7647-g7647.

[23] UNICEF. Taking Child Protection to the Next Level in Kenya. Glob Aff [Internet]. 2016;(June):25. Available from: https://www.unicef.org/protection/files/Kenya_CP_system_case_study.pdf

[24] Fish D. Child protection. Bmj. 1996;313(7071):1548-9.

[25] Child Care Reforms. An Analysis of Child-Care Reform in Three African Countries Summary of Ghana Rwanda. 2015;(March).

[26] Siu GE, Wight D, Seeley J, Namutebi C, Sekiwunga R, Zalwango F, et al. Men's Involvement in a Parenting Programme to Reduce Child Maltreatment and Gender-Based Violence: Formative Evaluation in Uganda. Eur J Dev Res. 2017;29(5):1017-37.

[27] Knight L, Allen E, Mirembe A, Nakuti J, Namy S, Child JC, et al. Implementation of the Good School Toolkit in Uganda: A quantitative process evaluation of a successful violence prevention program. BMC Public Health. 2018;18(1):1-13.

[28] Cardoso I de B. Violence against children and care in Africa. A discussion paper. 2017;76.

[29] Psychosocial N, Guidelines S, Children V. Department of Children Services National Psychosocial Support Guidelines for Orphans and Vulnerable Children. 2015;(October).

[30] Mutavi T, Obondo A, Kokonya D, Khasakhala L, Mbwayo A, Njiri F, et al. Incidence of depressive symptoms among sexually abused children in Kenya. Child Adolesc Psychiatry Ment Health [Internet]. 2018;12(1):1-8. Available from: https://doi.org/10.1186/s13034-018-0247-y

[31] Kaltenbach E, Hermenau K, Nkuba M, Goessmann K, Hecker T. Improving Interaction Competencies With Children-A Pilot Feasibility Study to Reduce School Corporal Punishment. J Aggress Maltreatment Trauma. 2018;27(1):35-53.

[32] Macdonald, Livingstone, J. Hanratty, McCartan, Cotmore, Cary, Glaser, Byford, Welton, Bosqui, Bowes, Audrey, Mezey, Fisher R\& C. The effectiveness, acceptability and cost-effectiveness of psychosocial interventions for maltreated children and adolescents: An evidence synthesis. Health Technol Assess (Rockv). 2016;20(69).

[33] Guidelines WHO, Response HS, Maltreatment C, Guideline WHO, Committee R, Guidelines WHOC. Technical Report WHO GUIDELINES FOR THE HEALTH SECTOR RESPONSE TO CHILD MALTREATMENT This technical report includes the recommendations for the WHO Guidelines for the Health Sector Response to Child Maltreatment that were approved by the WHO Guideline Rev. 2019;(August).

Citation: Eunice. Ndyareeba (MED), et.al. "Psychosocial Support Interventions for Children with a History of Maltreatment: The Situation in the East African Community. An Integrative Systematic Review" International Journal of Humanities Social Sciences and Education (IJHSSE), vol 7, no. 10, 2020, pp. 101-108. doi: https://doi.org/10.20431/2349-0381.0710013.

Copyright: (C) 2020 Authors. This is an open-access article distributed under the terms of the Creative Commons Attribution License, which permits unrestricted use, distribution, and reproduction in any medium, provided the original author and source are credited. 